Histórias em quadrinhos na geografia escolar

\title{
Comics in school geography
}

Pedro Dias Mangolini Neves* Felipe Gomes Rubira**

\section{Resumo:}

A presente pesquisa foi desenvolvida com alunos do $6^{\circ}$ ano do Colégio Estadual Vital Brasil em Maringá (PR). O tema principal das aulas foi o campo: relaçôes sociais existentes e principais atividades, como os tipos de agricultura (Moderna, Comercial, Tradicional e Subsistência) e pecuária (Intensiva e Extensiva). Para o melhor aprendizado objetivou-se realizar experiência didática alternativa de ensino, correlacionada a elaboração de história em quadrinhos, a qual foi pautada na síntese da temática apresentada durante as aulas. Os resultados evidenciaram que com a história em quadrinhos, o despertar da curiosidade, interesse e desejo de aprender dos alunos foi maior, os quais foram motivados pela inserção lúdica ao conteúdo, deflagrando maior eficiência em relação aos métodos tradicionais de ensino.

\begin{abstract}
:
The present research was developed with students of the 6th year of the Vital Brazil State College in Maringá (PR). The main theme of the classes was the field: existing social relations and main activities such as the types of agriculture (Modern, Commercial, Traditional and Subsistence) and livestock (Intensive and Extensive). For the best learning, the objective was to carry out alternative didactic teaching experience, correlated with comic book elaboration, which was based on the synthesis of the theme presented during the classes. The results showed that with the comics, the students' curiosity, interest and desire to learn was greater, which were motivated by the playful insertion of the content, provoking greater efficiency in relation to traditional teaching methods.
\end{abstract}

\author{
* Doutorando em Geografia - \\ Universidade Federal de Goiás \\ ** Doutorando em Geografia \\ - Universidade Estadual de \\ Campinas
}

Palavras-chave:

ensino da geografia; história em quadrinhos; o campo.

Keywords: teaching of geography; comic books; the field. 


\section{INTRODUÇÃO}

E sta pesquisa foi realizada com alunos do $6^{\circ}$ ano do Colégio Estadual Vital Brasil em Maringá (PR). O tema abordado foi o campo, suas relaçóes sociais existentes e principais atividades econômicas. Considerando esse conteúdo geográfico, foram utilizadas histórias em quadrinhos (HQ's) como recurso didático, na tentativa de despertar a curiosidade, interesse e desejo de aprender dos alunos, objetivando melhor assimilação do conteúdo.

Segundo Anselmo (1975), a origem da história em quadrinhos associa-se a pré-história, quando homens das cavernas faziam pinturas rupestres representando sua história por meio de imagens. Séculos mais tarde surgiram os hieróglifos, desenhados pelos egípcios, os quais também se constituíram como maneira de se comunicar por meio de figuras. Segundo estudiosos antigos, o balâo utilizado para caracterizar o diálogo, remete a 1370, quando uma frase dita por um romano foi gravada em uma tábua. Desde então, o texto e a ilustração apareceram juntos cada vez com mais frequência.

No Brasil, as HQ's surgiram em 1905, quando as revistas Tico-Tico, de Buster Brown, foram traduzidas para o português. Por muitos anos, as editoras financiavam somente publicaçóes provenientes da Europa e América do Norte, sem abrir espaço para desenhistas brasileiros. Até a década de 1940 surgiram revistas que se dedicavam principalmente ao público infantil, mas somente com ilustraçóes estrangeiras (LUYTEN, 1984). Assim, impulsionada pelo surgimento de jornais e revistas, as HQ's, enfim tornaram-se populares.

A reflexão sobre estes materiais alternativos, pouco utilizados como recurso didático no processo ensino-aprendizagem em Geografia, culminou no desenvolvimento desta pesquisa. Nesta perspectiva, a proposta de ensino de Geografia, relacionada às histórias em quadrinhos foi empregada e aplicada em sala de aula.

Desta maneira, este estudo objetiva realizar experiência didática alternativa de ensino, correlacionada a elaboração de história em quadrinhos, a qual foi pautada na síntese da temática apresentada durante as aulas. Simultaneamente, objetiva evidenciar a importância e contribuição das HQ's para o ensino de Geografia.

Sabe-se por meio de Dezotti e Ortiz (2010), Pereira (2011), Santos e Chiapetti (2011), Lima et al. (2014) e Pereira e Bianco (2014) que para despertar curiosidade e envolver o aluno com a aula, torna-se necessário incorporar ferramentas lúdicas de ensino.

Presume-se então que a utilização das histórias em quadrinhos como prática pedagógica atinja estes objetivos.
Contudo, salienta-se que apesar de ser um recurso válido, náo deve ser trabalhado sozinho. Aprender pode ser divertido; ao mesmo tempo em que desperta o interesse, aguça o senso crítico dos alunos.

Com base nestes argumentos, cabe ao professor buscar novos recursos para o ensino, utilizar materiais alternativos em sala de aula e aplicar métodos não convencionais que encantem o aluno, fazendo com que sinta vontade de estudar.

Nesta perspectiva, verifica-se que as revistas em quadrinhos representam mais que um conjunto de folhas. Possuem a capacidade de agregar em si processos produtivos, funçóes que dependem de quem a produz e para quem é produzido. Apresenta-se então como manifestaçáo criativa e cultural (CIRNE, 1990).

Deste modo, Eisner (1995) define a importância da história em quadrinhos como sendo:

[...] uma habilidade estudada, que pode ser aprendida, que se baseia no emprego imaginativo do conhecimento da ciência e da linguagem, assim como da habilidade de retratar ou caricaturar e de manejar as ferramentas do desenho (EISNER, 1995, p.144).

Para Eisner (1995), a arte sequencial, especialmente nas histórias em Quadrinhos, caracteriza-se como habilidade estudada, que pode ser aprendida, a qual se baseia no emprego imaginativo do conhecimento da ciência e da linguagem, assim como da habilidade de retratar ou caricaturar e de manejar as ferramentas do desenho. Segundo Eisner (1995), essa linguagem envolve diversas áreas do conhecimento humano, desenvolvendo habilidades mentais e motoras.

Assim, concebendo a história em quadrinhos como recurso para a prática de ensino em Geografia, foram trabalhados temas da Geografia Agrária, capazes de despertar a noção de espaço geográfico no cotidiano dos alunos.

Para isto, algumas revistas em quadrinhos, que abordam conflitos por terra, foram utilizadas em sala de aula como fonte de inspiração, para fins pedagógicos e didáticos. A elaboração de HQ's, por parte dos alunos, possibilitou o estímulo da capacidade criativa e de comunicação dos mesmos.

Desta maneira, o trabalho aplicado apresentou-se importante para que os alunos compreendessem as relaçóes existentes no campo, já que em sua maioria vivem no espaço urbano e não convivem com a vida rural.

Tal fato associa-se a urbanização acentuada no Brasil durante as décadas de 1980, 1990 e 2000. As discussões atuais tratam mais do meio urbano do que as questôes rurais. Discussóes como os conflitos no campo são geralmente esquecidas e não dada a real importância. 
Sabendo disto, foram aplicadas discussóes sobre: a pecuária, agricultura, relaçóes com as limitaçóes impostas pelo clima e diferentes tipos de alimentos presente no dia-a-dia. Estes conhecimentos permitiram que os alunos associassem o desenvolvimento de determinadas culturas as peculiaridades climáticas em um país de dimensão continental como o Brasil.

Também foram abordados temas como: reforma agrária, migração do campo para a cidade e processo de colonização que estabeleceu a situação fundiária no Brasil, destacando a regime de sesmaria. Por meio das atividades propostas as crianças conheceram e associaram personagens a elementos da paisagem.

\section{METODOLOGIA}

Este artigo baseou-se em revisões bibliográficas e reflexóes teóricas por meio de trabalhos clássicos e recen-

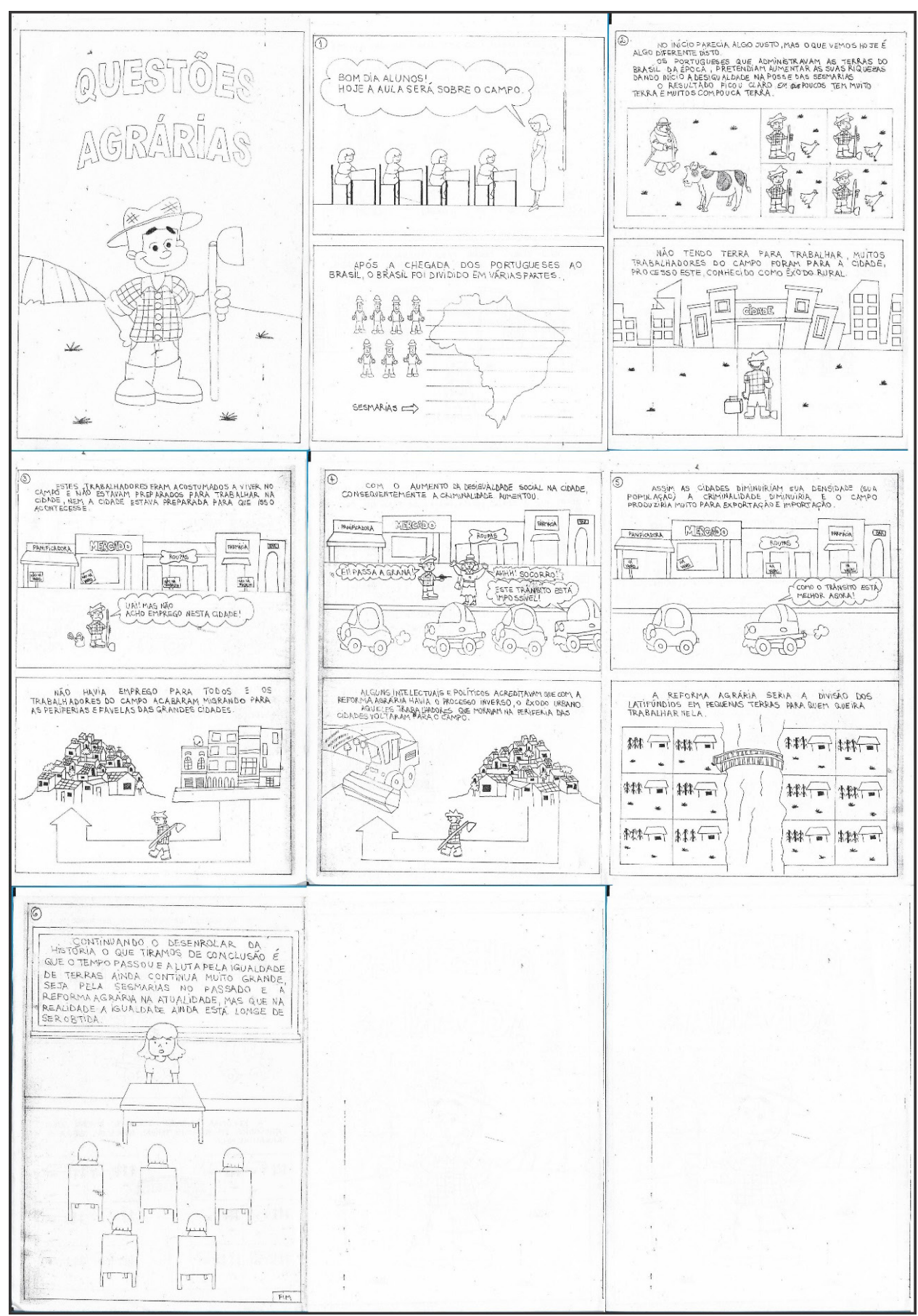

Figura 1: História em Quadrinhos exemplificando a questão agrária elaborada pelos autores Fonte: Autores (2010) 
tes publicados em congressos, periódicos e livros. Pode-se mencionar: Calazans (2004), Tussi (2005), Vergueiro (2006), Barbosa et al. (2007), Deffune (2010), Costa (2012), Melo et al. (2013) e Pereira e Bianco (2014).

Assim, foram analisadas experiências pretéritas no ensino da Geografia através deste recurso didático, objetivando avaliar a história em quadrinhos como prática pedagógica no ensino por meio de linguagem alternativa, capaz de potencializar a aprendizagem da Geografia e a construção da leitura geográfica.

Posteriormente, realizou-se estudo e planejamento do conteúdo que seria trabalhado em sala de aula, o qual será descrito no item 4 deste estudo.

Desta maneira, foi elaborada uma história em quadrinhos (Figura 1) baseada na síntese do conteúdo lecionado em sala de aula, para os alunos compreenderem o assunto ministrado e utilizarem como modelo, para o exercício que posteriormente seria proposto (elaboração da própria HQ).

Ao final da regência, no ano de 2010, foi solicitado a todos os alunos que elaborassem sua própria história em quadrinho, a qual deveria possuir conteúdo correlacionado as discussóes evidenciadas durante as aulas. Ficando a critério dos próprios estudantes a escolha de qualquer tema abordado.

\section{USO DE HISTÓRIAS EM QUADRINHOS NO ENSINO DE GEOGRAFIA}

Para a Geografia, a linguagem das histórias em quadrinhos caracteriza-se como forma de leitura própria, a qual se constitui através de textos e imagens. Portanto, acredita-se que o uso desse veículo de expressão auxilia na construção da leitura geográfica e propicia inserção mais ativa no espaço vivido (DEFFUNE, 2010).

Dialogando com a Geografia, as histórias em quadrinhos podem ser apresentadas diante de grande e vasto conteúdo, que é inerente a ela. O campo de estudo da Geografia baseia-se na percepçáo e representação espacial das pessoas, considerando que nesse arsenal de instrumentos, cabem também as expressões visuais, artística ou literárias, construídas pelos seres humanos por meio da sua vivência no espaço (RAMA e VERGUEIRO, 2006).

No intuito de superação do ensino de Geografia baseado somente no esquema "Terra e Homem", Vesentini (1986) aponta que os melhores pedagogos são aqueles conscientes de como a imaginação constitui excelente ajuda para o raciocínio científico. Dessa forma, considera as histórias em quadrinhos fundamentais para o exercício da criatividade em sala de aula.
Assim, a Geografia ganha um leque de possibilidades para melhor atingir a percepção do público discente, abordando em sua prática pedagógica, a música, o cinema, a literatura e o objeto em questáo desta reflexão, as histórias em quadrinhos, que reverberam em ambos os hemisférios cerebrais de quem as lê: o esquerdo (racional) com as informaçóes científicas e termos técnicos e o direito (criativo) com os desenhos e criaçôes imagéticas "lúdicas", os quais auxiliam a mente a recriar sobre o que está vendo e lendo, e questiona a necessidade de se resgatar a beleza poética na vida, em contraponto à frieza cientificista cartesiana de um pensamento racional exclusivista (DEFFUNE, 2010).

Diante dos diversos recursos didáticos existentes, as histórias em quadrinhos constituem-se como meio de complementar o conteúdo dos livros didáticos de maneira atrativa. Vergueiro (2006) evidencia a importância desse meio de comunicação e a influência que o mesmo exerce na sociedade:

Sem dúvida, os quadrinhos representam hoje, no mundo intei-
ro, um meio de comunicaçáo de massa de grande penetraçáo
popular. Nos quatro cantos do planeta, as publicaçóes do gê-
nero circulam com uma enorme variedade de títulos e tiragens
de milhares ou, às vezes, até mesmo milhóes de exemplares, avi-
damente adquiridos e consumidos por um público fiel, sempre
ansioso por novidades. Mesmo o aparecimento e a concorrência
de outros meios de comunicaçáo e entretenimento, cada vez
mais abundantes, diversificados e sofisticados, não impediram
que os quadrinhos continuassem, neste início de século, a atrair
um grande número de fấs (VERGUEIRO et al. 2006, p. 07).

As HQ's, ainda na era da tecnologia, continuam em "alta", isso elucida a sua importância e nos permite observar as contribuiçóes que podem oferecer aos alunos em relação a leitura do espaço geográfico do qual fazem parte. Esse recurso pedagógico também vai proporcionar o trabalho das competências básicas, que se faz necessária para os alunos das séries iniciais e se estende até o final do Ensino Médio. Sobre essas competências Selbach (2010) escreve:

Essas competências, conforme o nível de aprendizagem do aluno, envolvem a aprendizagem e utilização de múltiplas habilidades, como, por exemplo, reconhecer, analisar, comparar, relacionar, classificar, deduzir, propor soluçóes, avaliar, verificar, perceber, entender, identificar, compreender e muitas outras, também essenciais a outras disciplinas. (SELBACH, 2010, p. 99).

Nesta temática, para Kozel et al. (2006), a Geografia sempre esteve associada às imagens. Em um primeiro momento, com o sentido de transmitir informaçôes sobre os espaços desvendados e, posteriormente, como forma de comunicação/representação do espaço físico. 
Desta maneira se insere todo o instrumental conhecido: mapas, cartas topográficas, sensoriamento remoto, fotografias aéreas, imagens de satélites, paisagens, entre outros. O campo de estudo geográfico, que se baseia na percepção e representação espacial dos indivíduos, considera que nesse arsenal de instrumentos cabem também as expressóes visuais, artísticas ou literárias, construídas pelos seres humanos, por meio da sua vivência no espaço.

\section{CONTEÚDOS TRABALHADOS}

Foram trabalhados ao longo da regência temas relacionados ao campo. Neste momento torna-se importante esclarecê-los.

Inicialmente optou-se pela análise da agricultura, tema essencial para que os alunos compreendessem que todos os alimentos têm determinada origem, os quais provêm desta atividade econômica e da pecuária. Optou-se por destacar os diferentes tipos de agricultura. Assim, durante as aulas, foram debatidas as principais características de cada modelo.

Desta maneira, durante as discussôes pautadas para caracterização dos tipos de agricultura foram detalhados os equipamentos, espaço específico para a produção, mão de obra utilizada, em conjunto com a importância que cada uma exerce para a sociedade atual e para economia do Brasil.

Assim, para a agricultura moderna foram evidenciadas a utilização de adubos, sementes selecionadas, tratores, agrotóxicos para controlar os diversos tipos de pragas e sistemas de irrigação, essenciais em regióes áridas e semiáridas. Fatores determinantes para obtenção da maior produtividade.

Em relação a agricultura comercial foram expostas discussóes correlacionadas ao cultivo de soja, milho, cana-de-açúcar, algodáo e laranja, sob a perspectiva de exportação e produção de matérias primas para fabricação industrial de roupas, etanol e derivados industrializados direcionados a posterior comercializaçáo.

Quanto a agricultura tradicional, foram destacadas as condiçóes socioeconômicas dos produtores, assim foi exposto o limitado capital para investir em sementes selecionadas, correção dos solos e equipamentos, os quais acarretam em baixa produtividade. Foram evidenciados os conhecimentos técnicos básicos por parte do produtor, os instrumentos de trabalho opostos ao da agricultura moderna, predomínio da policultura e o tamanho das propriedades (minifúndios).

Para a caracterização da agricultura de auto consumo foram enfatizadas a utilização de pequenas pro- priedades, técnicas tradicionais de cultivo (arado de tração animal, enxada, rastelo e adubo natural, produção em quantidades menores, principais culturas produzidas (milho, mandioca, batata, feijão, arroz e hortaliça) e o objetivo de destinaçáo da mesma, tanto a própria família do agricultor, a qual garante a sobrevivência consumindo o que plantou, quanto para a alimentação da população brasileira, já que $70 \%$ da alimentação dos brasileiros provém da agricultura familiar, como aponta o estudo do IBGE (2006).

Por meio destas discussóes tornou-se oportuno frisar que o Brasil é considerado um país industrializado, ao mesmo tempo em que ocupa um dos primeiros lugares em produção agrícola e pecuária.

Para tanto, foi exposto que a pecuária também é uma atividade econômica desenvolvida em áreas rurais, a qual objetiva a criação de animais (equinos, aves, ovinos, suínos, bovinos, entre outros) para comercializá-los posteriormente, garantindo assim as necessidades de várias famílias brasileiras.

Neste momento, iniciaram-se as diferenciaçóes entre os tipos de pecuária (extensiva e intensiva). Em relação a pecuária extensiva foram evidenciadas o tamanho das propriedades, obtenção de matérias-primas (carne, leite, couro, lá, entre outros) e o modo de produção, relacionado a criação a pasto, menor produção correlacionada ao baixo investimento.

Quanto a agricultura intensiva, foram destacadas características opostas as da extensiva, baixa necessidade de mão de obra, elevado investimento, técnicas modernas (tecnologia), confinamento dos animais e manipulação genética (alto investimento com raçóes e remédios). Fatores responsáveis pelo aumento de produtividade.

A partir destas discussóes iniciaram-se as consideraçóes sobre o clima, as potencializaçôes e limitaçóes impostas pelo mesmo na produção agrícola, em conjunto com o uso inadequado das técnicas produtivas, contaminação por agrotóxicos, erosão, assoreamento de rios e desmatamento, fatores determinantes para a suscitação de problemas adversos a produção agrícola.

Fazer qualquer análise prospectiva sobre a agricultura brasileira impóe que se faça antes consideraçôes sobre as variações climáticas do último século. Isto porque grande parte dos problemas e soluçóes que se apresentam estão relacionados com fatores climáticos, os quais mantém relação direta com avanços e atrasos contidos na atividade agrícola.

Assim, foram evidenciados gráficos e figuras elaborados pelo Intergovernmental Panel on Climate Change (IPCC) em 2001 vinculados ao aquecimento 
global, os quais indicam aumento da concentração de $\mathrm{CO}^{2}$ na atmosfera, elevação da temperatura global, da água oceânica e ascensão do nível do mar $(10$ a $20 \mathrm{~cm}$ no século XX). Por meio destas discussóes foram elucidadas as consequências que tais alternâncias climáticas poderiam acarretar para a produção agrícola no Brasil, diminuindo a área favorável para o plantio de diversas agriculturas por meio da retraçáo da faixa tropical e expansão de regióes semiáridas (Figura 2).

Nesta temática, foram evidenciados diferentes padróes climáticos em um país com vasta extensão territorial como o Brasil, o semiárido, equatorial, tropical e subtropical. Destacou-se as áreas sob domínio climático tropical, responsáveis por possibilitar duas ou mais safras por ano, garantindo maior produtividade.

Exemplos didáticos foram apresentados. Exemplificou-se que as plantas cultivadas se desenvolvem melhor no clima de seu lugar de origem, possibilitando maior produtividade: o trigo, uva e soja em regióes de climas temperados; banana, cana-de-açúcar e coco em climas tropicais.

Após estes assuntos iniciaram-se as discussões sobre as questóes agrárias, por meio de debates pautados no campesinato, latifúndio e agronegócio, compreendidos como diferentes modelos de desenvolvimento para o campo, os quais se confrontam no processo de reprodução social e reprodução do capital.

Deste modo, salientou-se que a questão agrária configura-se como a relação entre a concentração fundiária e a reforma da desigual estrutura agrária que está e, foi concentrada, ao longo de um processo histórico, o qual se iniciou na colonizaçáo portuguesa no Brasil (responsável pela instauração do regime de sesmarias), onde apenas poucos "puros" obtinham extensas áreas para produzir, enquanto a maioria da população não possuía direito a posse da terra por serem escravos ou indígenas (OLIVEIRA, 2007).

O regime de sesmarias foi suspenso em 1822 e em 1850 foi implementado a Lei de Terras no Brasil, a qual consistia na obtençáo da posse de terras apenas por meio de compra e titulaçáo disponibilizada por cartório (MARTINS, 1997). A implementação desta lei foi uma resposta a abolição da escravatura e a hipotética possibilidade dos "ex-escravizados", quando tivessem sua carta de alforria, tomassem posse de terras brasileiras. Também se constituiu como estratégia para que os imigrantes europeus e, os brasileiros que não possuíam riquezas, tivessem que vender sua força de trabalho para a elite brasileira, já que não obtinham terras.

Segundo Sorj (1986) e Martins (1997), mesmo com a crise de 1929 e diminuição do poder político da oligarquia rural (baseada neste período principalmente em cafeicultores) pelo poder político da burguesia industrial, os ruralistas se mantiveram com certo grau de importância ao diversificar a produção de agricultura em monocultivos para exportação.

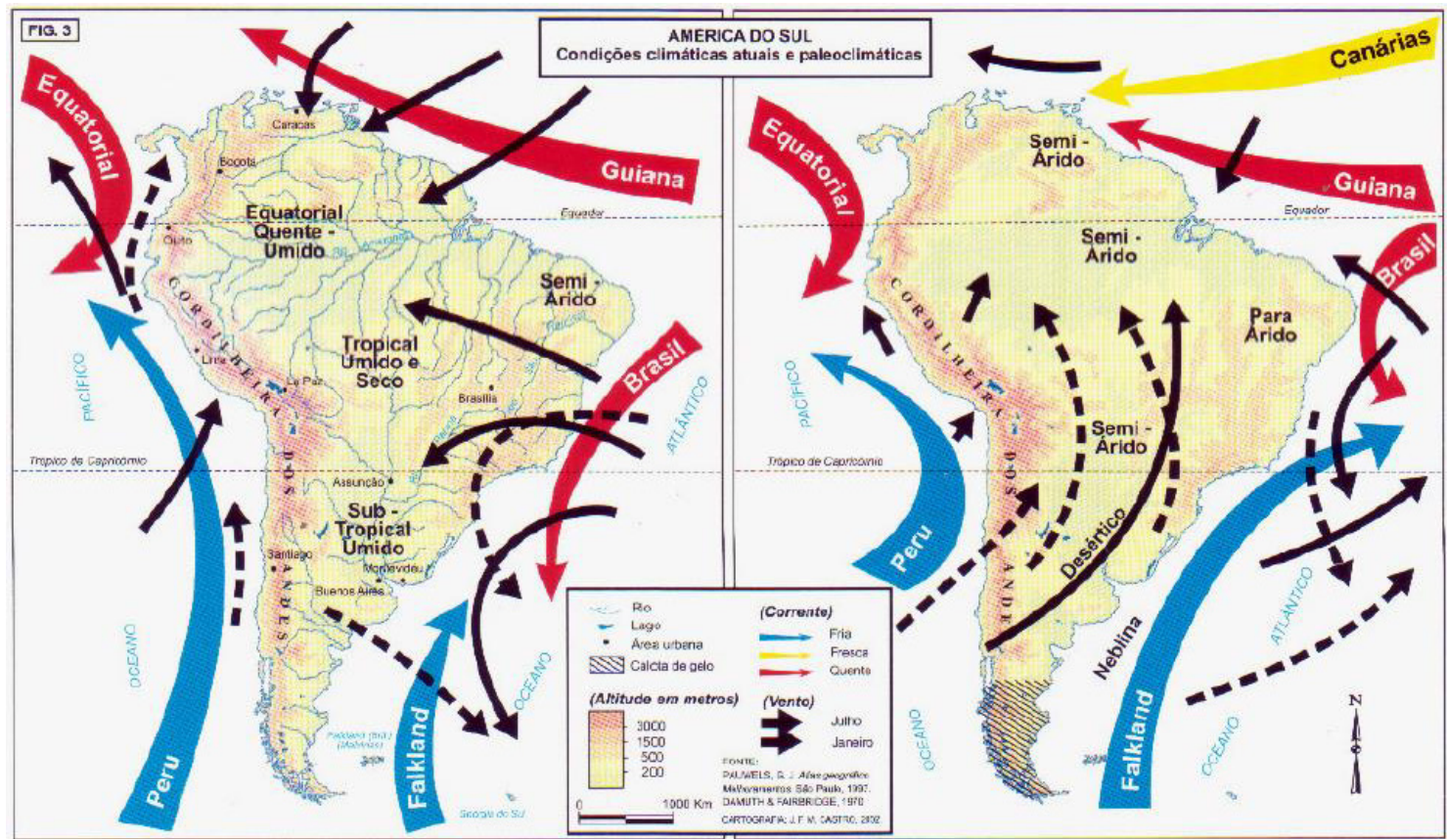

Figura 2: Condiçốes climáticas atuais (períodos quentes e úmidos) e condiçôes paleoclimáticas durante eventos globais de resfriamento (períodos quentes e secos)

Fonte: Damuth e Fairbridge (1970). In: Viadana (2002) 
Neste período, parte dos camponeses sobreviviam por meio da agricultura de auto consumo e outra porção iniciava um processo de migração para a cidade, buscando melhores condiçôes de reprodução social.

No fim da década de 1950, começaram a surgir no campo militâncias políticas que passaram a contestar a concentração fundiária e a consequente desigualdade social no Brasil, pressionando o governo para a realização de reforma agrária no país.

Este movimento ganhou força no governo João Goulart (presidente progressista que tratava a reforma agrária como fundamental para uma modernização do Brasil), porém foi frustrado pelo Golpe Militar de 1964 que, num grande acordo nacional entre a oligarquia rural, burguesia industrial, militares e políticos marcou o início do Regime Militar, o qual perdurou por vinte e um anos. (SORJ, 1989).

Neste período houve a modernização da agricultura brasileira em grandes e médias propriedades por meio de créditos rurais (subsídios do Estado) para a compra de maquinário, adubos químicos e agrotóxicos (na chamada Revolução Verde).

Com esta "modernização da agricultura" a desigualdade no campo (e no Brasil) aumentou e a estrutura fundiária tornou-se cada vez mais desigual, acentuando a migração de camponeses para as cidades e tornando o campo brasileiro cada vez mais vazio, com cidades mais povoadas. Iniciaram-se assim a intensificação de problemas urbanos, como desigualdade social, pobreza, criminalidade e violência.

Com o fim da ditadura, em 1988, foi elaborada nova Constituição Federal e houve, a esperança da reforma brasileira ser enfim elaborada, porém foi barrada pelos interesses dos grandes proprietários de terra, os quais possuem muita força política.

Nas décadas que se seguiram, 1990, 2000 e 2010, houveram implementaçóes de assentamentos, tanto no governo Fernando Henrique Cardoso, como no Governo Lula, contudo muito aquém do que o Brasil necessita.

Desta maneira, após as discussóes dos conteúdos apresentados nesta seção iniciaram-se as atividades relacionadas a elaboração das HQ's por parte dos alunos.

\section{RESULTADOS OBTIDOS}

Os resultados obtidos foram satisfatórios, por entender que a maioria dos alunos conseguiram assimilar o conteúdo. Houve participação e interatividade acima do normal, em função da realização da atividade em dupla, a qual demonstrou-se capaz de estimular os estudantes por meio de debates provenientes da assimilação dos ensinamentos e posterior elaboração das HQ's.

A metodologia lúdica aplicada como prática pedagógica demonstrou-se eficaz. O conteúdo denso e de difícil compreensão, por meio desta aplicação didática, apresentou-se como excelente recurso de fixação do conteúdo.

Assim, foram entregues 14 trabalhos, sendo 13 em dupla e um em trio. Três alunos não realizaram o trabalho pois faltaram no dia da aplicação do projeto. Destes trabalhos, um foi relacionado a questão da colonização brasileira, descrevendo a divisão da terra em capitanias hereditárias (Figura 3).

Cinco trabalhos deram enfoque a questão da migração da população rural para os centros urbanos ( $\mathrm{Fi}-$ gura 4). Esta temática teve maior aceitação pela turma, isto porque alguns alunos possuíam avós que também migraram do campo para as cidades.

O restante, oito trabalhos, foram referentes a agricultura e a pecuária, exemplificando a vida no campo e os tipos de produção (Figura 5). Temáticas que foram mais observadas por alunos que residem nos centros urbanos com difícil contato com o meio rural, os quais correlacionaram a agricultura somente com a produção de alimentos, não levando em consideraçáo o processo histórico e implicaçóes na desigualdade da estrutura fundiária brasileira.

Desta maneira, os resultados obtidos, por meio das HQ's desenvolvidas, evidenciaram variedade dos temas abordados em sala de aula. Aplicaçóes que foram desde as atividades no campo até a migração da população camponesa para a cidade e, suas implicaçôes. Estes resultados revelaram que o conteúdo trabalhado em sala de aula foi assimilado, confirmando que o processo de ensino-aprendizagem foi realizado com sucesso.

Com a aplicação de todo conteúdo, os alunos compreenderam a importância que o campo exerce no nosso dia a dia. Assimilaram a importância da relação entre campo e cidade para economia e sociedade brasileira por meio da abordagem proposta, em relação a produção agrícola, pecuária, condiçôes dos trabalhadores rurais, produtos finais e principais fatos históricos que determinaram a estrutura fundiária brasileira. Também aprenderam que por trás do produto final disponível no mercado há todo um processo envolvido no campo.

Portanto, os resultados das consideraçóes sobre a questão agrária, representados na forma de HQ's, foram surpreendentes, as quais apresentaram-se como excelente ferramenta para estimulação de reflexôes críticas profundas. 
Nome gueroma Sychalay e Ama Buotriz

1) Faça uma história em quadrinho sobre trabalhadores do campo apresentando seus

principais fatos.

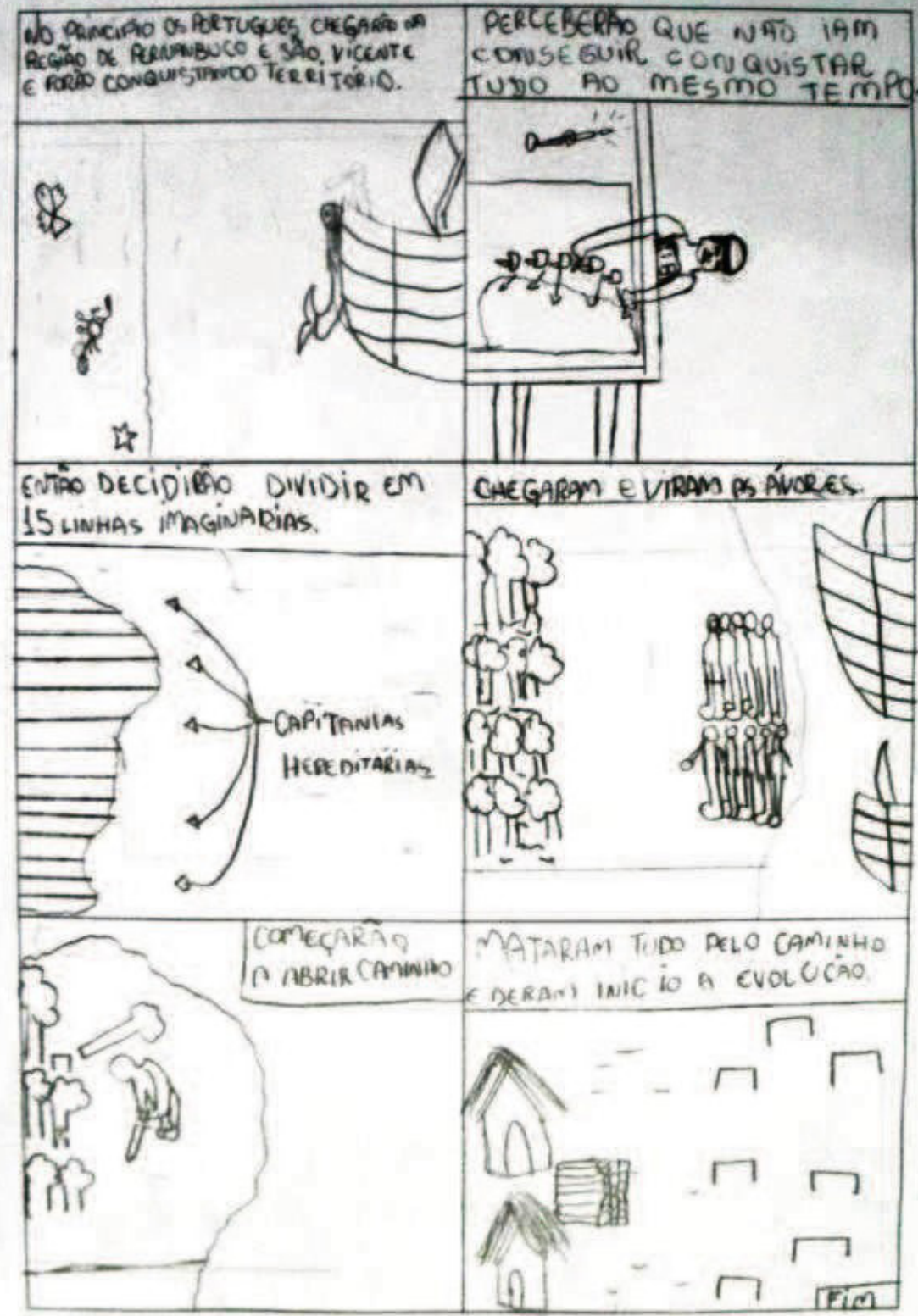

Figura 3: Trabalho de alunas Geovana e Ana Beatriz exemplificando o início da apropriação de terras do Brasil em Capitanias Hereditárias $(2010)$

Fonte: Autores (2010) 


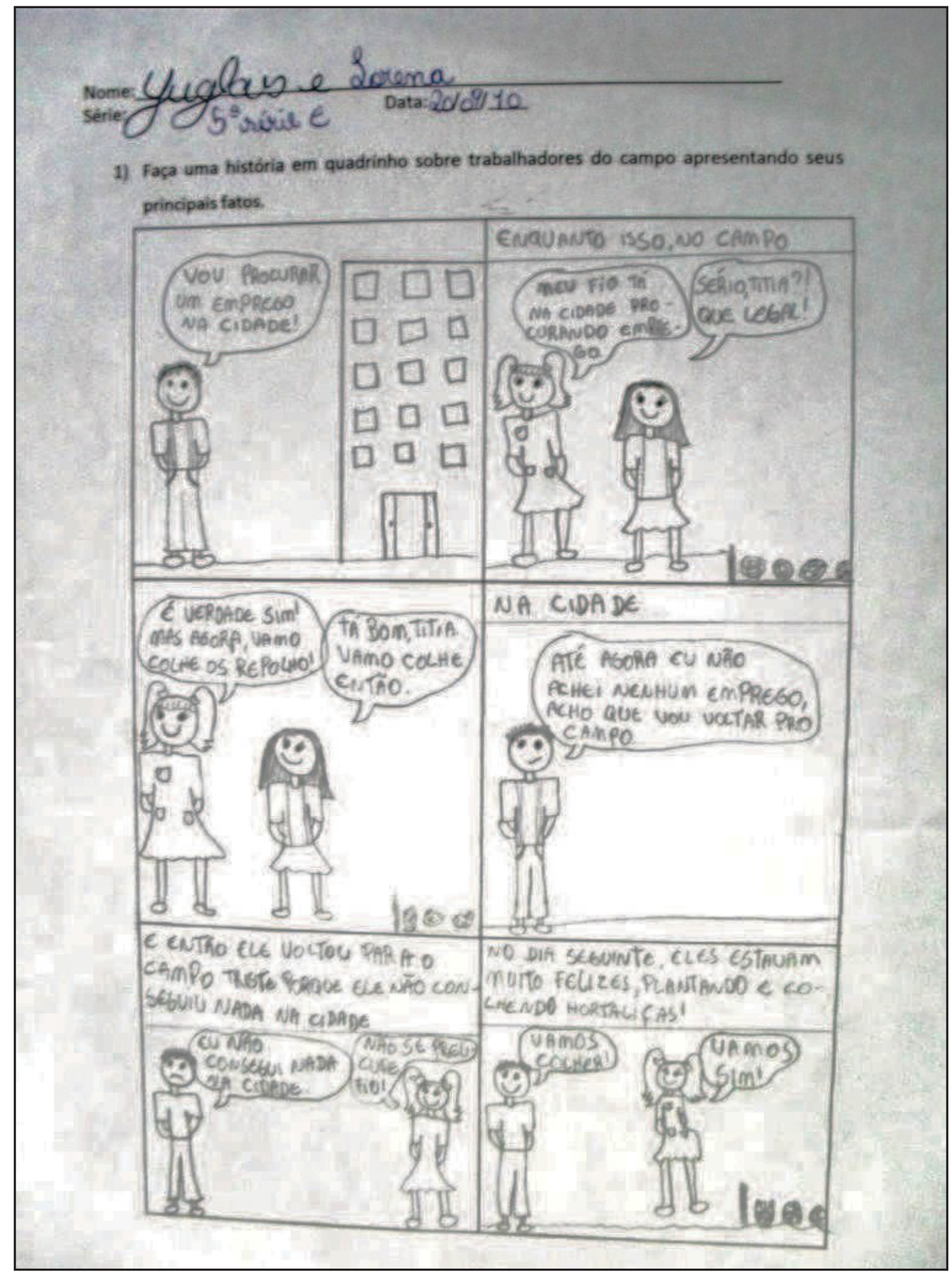

Figura 4: Trabalho de Yuglas e Lorena exemplificando a migração da população camponesa para os centros urbanos (2010) Fonte: Autores (2010)

Geografia, Ensino \& Pesquisa, Vol. 21 (2017), n.3, p. 118-129

ISSN: 2236-4994 DOI: 10.5902/2236499424546 


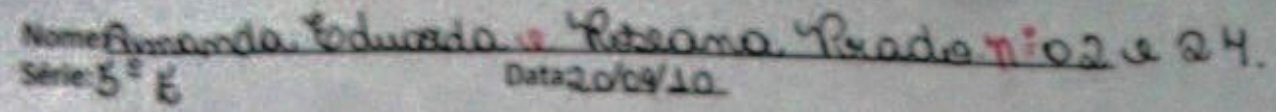

1) Faga uma histibia em quadrinho sobre trabalhadores do campo apresentando seus principas fatos.

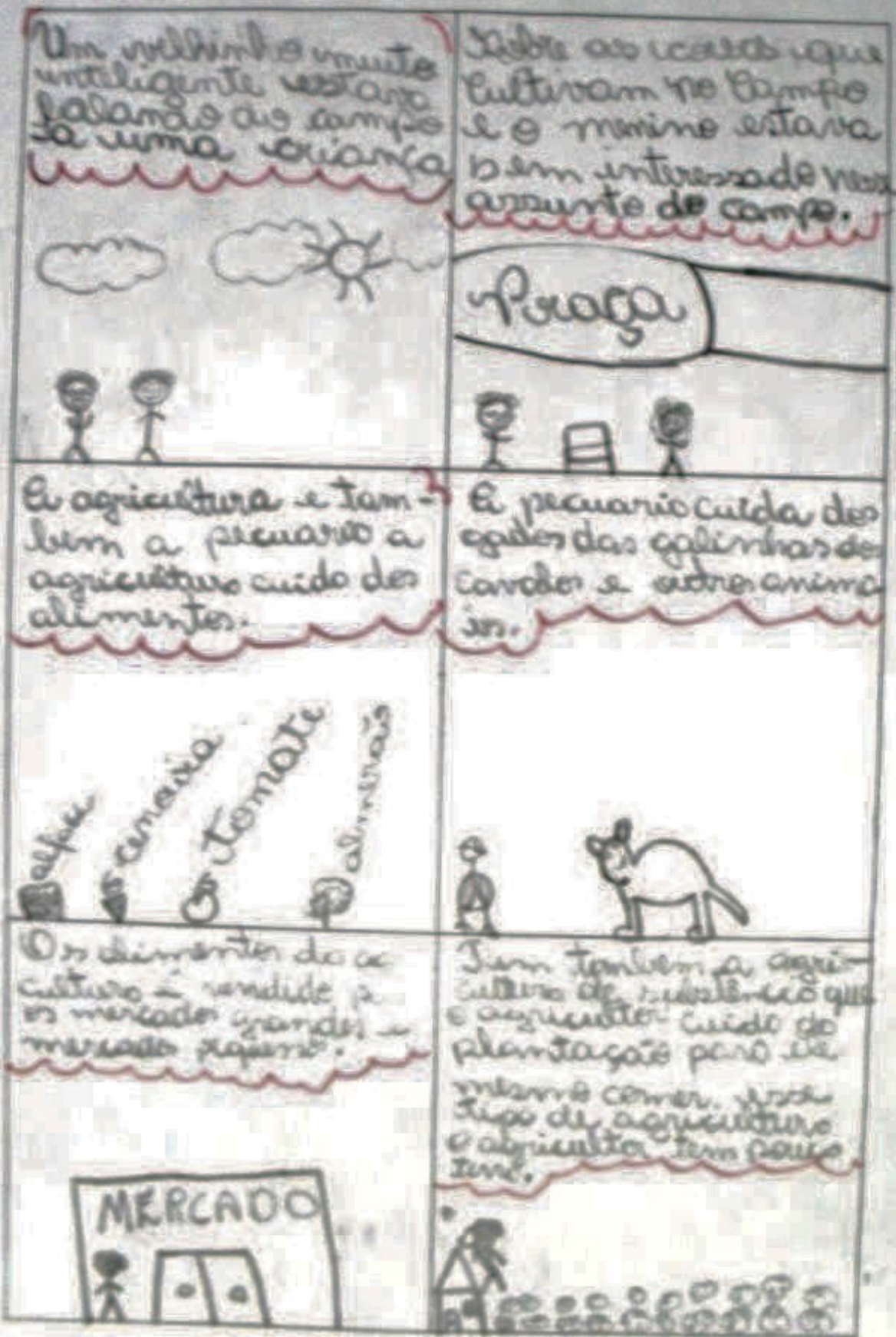

Figura 5: Trabalho de Amanda Eduarda e Roseana exemplificando os diferentes tipos de agricultura e pecuária (2010) Fonte: Autores (2010)

Geografia, Ensino \& Pesquisa, Vol. 21 (2017), n.3, p. 118-129

ISSN: 2236-4994 DOI: 10.5902/2236499424546 


\section{CONSIDERAÇÓES FINAIS}

Esta pesquisa identificou a contribuição das HQ's nas aulas de Geografia, enfocando a utilização das mesmas como recurso pedagógico. Foi possível perceber que os alunos receberam bem esta prática, pois interagiram muito com a atividade.

Houve discrepância quanto a quantidade de HQ's em relaçáo cada assunto trabalhado. Os alunos souberam expressar melhor (durante a elaboração das HQ's) temáticas correlacionadas a agricultura e/ou pecuária, seguido do conteúdo relacionado ao êxodo rural.

Fato notado pela quantificaçáo dos trabalhos produzidos, haja visto que 57\% das HQ's elaboradas trataram sobre agricultura e pecuária; $35 \%$ sobre a migração da população camponesa para as cidades e $8 \%$ sobre a colonização brasileira, temática aliada a fatores históricos.

Findando este trabalho, foi possível notar que as HQ's se configuraram como excelente ferramenta pedagógica, essencial para que o professor consiga inferir se o aluno desenvolveu observação sistematizada e reflexiva sobre o conteúdo, pois a utilização deste recurso contribuiu para a livre expressão dos alunos, desvinculada de qualquer roteiro ou sistematização realizada pelo professor.

Salienta-se que esta atividade proporcionou o desenvolvimento do potencial do aluno em assimilar o conteúdo e se expressar livremente, na forma de desenhos.

\section{REFERÊNCIAS}

ANSELMO, Z. A. Histórias em quadrinhos. Petrópolis: Vozes, 1975.

BARBOSA, A.; RAMOS, P.; VILELA, T.; RAMA, A.; VERGUEIRO, W. Como usar as Histórias em Quadrinhos na Sala de Aula. $3^{a}$ ed. São Paulo: contexto 2007.

CALAZANS, F. História em quadrinhos na escola. São Paulo: Paulus, 2004.

CIRNE, M. História crítica dos quadrinhos brasileiros. Rio de Janeiro: Ed. Europa: FUNARTE, 1990.

COSTA, R. M. As histórias em Quadrinhos como Construção da Leitura Geográfica. In: ENCONTRO NACIONÁL DE GEÓGRAFOS, 16., 2010, Porto Alegre.

DAMUTH, J. E., FAIRBRIDGE R. W. Equatorial Atlantic deep arkosic sands and ice age aridity in tropical South
America. Geological Society of American Bulletin, n. 81, 1970.

DEFFUNE, G. Relato de uma experiência de história em quadrinhos no ensino da Geografia. Boletim de Geografia, Maringá, v. 28, n. 1, p. 157-169, 2010.

DEZOTTI, M. S.; ORTIZ, A. C. M. O ensino de Geografia em escolas de educação básica na cidade de Santa Maria, RS: uma análise metodológica. Disc. Scientia. Série: Ciências Humanas, Santa Maria, v. 11, n. 1, p. 79-91, 2010.

EISNER, W. Quadrinhos e Arte Sequencial. 2. Ed. São Paulo: Martins Fontes, 1995.

IBGE - INSTITUTO BRASILEIRO DE GEOGRAFIA E ESTATÍSTICA. Censo Agropecuário 2006. Ministério do Desenvolvimento Agrário e Ministério do Planejamento, Orçamento e Gestão, 2006.

INTERGOVERNMENTAL PANEL ON CLIMATE CHANGE - IPCC. Climate Change 2001: the scientific basis. Contribution of Working Group I to the Third Assessment Report of the Intergovernmental Panel on Climate Change. Cambridge: Cambridge University Press, 2001. $881 f$.

KOZEL, S.; SILVA, J. C.; GIL FILHO, S. F. (Orgs.). Da percepção e cognição à representação: reconstruçôes teóricas da geografia cultural e humanista. São Paulo: Terceira Margem, 2006.

LIMA, H. H. N.; OLIVEIRA, A. D. A.; MESQUITA, A. A. Google Maps como instrumento didático-pedagógico no ensino da Geografia: um estudo de caso com os alunos do $6^{\circ}$ ano do ensino fundamental do colégio de aplicação CAP/UFAC. South American Journal of Basic Education, Technical and Technological, v.1, n.1, p. 140-145, 2014.

LUYTEN, S. M. B. Histórias em quadrinhos: leitura crítica. São Paulo: Edições Paulinas, 1984

MARTINS, J. de S. A questão agrária brasileira e o papel do MST. In: STÉDILE, J. P. (org.). A reforma agrária e a luta do MST. Petrópolis: Vozes, 1997.

MELO, K. C.; MEDEIROS, A. F.; SILVA A. A. Uma Linguagem alternativa no ensino escolar: as histórias em quadrinhos na mediação do ensino e aprendizagem da geografia. Ateliê Geográfico, Goiânia-GO, v. 7, n. 1, p.260-283, 2013

OLIVEIRA, A. U. Modo de Produção Capitalista, Agricultura e Reforma Agrária. São Paulo: Labur Ediçôes, 2007.

PEREIRA, S. M.; BIANCO, A. A. G. Uso de histórias em quadrinhos digitais no ensino de Ciências e Química. In: Simpósio Nacional de ensino de Ciência e Tecnologia, 4., 2014, Ponta Grossa, PR. Anais... Ponta Grossa, p.1-12, 2014. 
PEREIRA, S. S. Reflexóes sobre a prática de ensino e os recursos adotados nas aulas de Geografia: a utilização de músicas em sala de aula por professores do município de Campinas Grande, PB. Geosaberes, Fortaleza, v. 2, n. 4, p. 88-99, ago. / dez. 211.

RAMA, A.; VERGUEIRO, W. Como usar as histórias em quadrinhos na sala de aula. 3. ed. São Paulo: Contexto, 2006, $155 f$.

SANTOS, R. C. E.; CHIAPETTI, R. J. N. Uma investigação sobre o uso das diversas linguagens no ensino de Geografia: uma interface teoria e prática. Geografia Ensino \& Pesquisa, v. 15, n.3, set./dez. 2011.

SELBACH, S. O ensino de Geografia para alunos que não irão ser geógrafos. In: ANTUNES, C.; SELBACH, S. Geografia e didática. Petrópolis, RJ: Vozes, p. 115-121, 2010.

SORJ, B. Estado e classes na agricultura brasileira. Rio de Janeiro: Editora Guanabara, 1986.

TUSSI, G. B. A história em quadrinhos como prática pedagógica no ensino de Geografia. In: ENCONTRO DE GEOGRAFOS DA AMÉRICA LATINAE, 10., 2005, São Paulo.

VERGUEIRO, W. Uso das HQs no ensino. In: RAMA, A.; VERGUEIRO, W. Como usar as histórias em quadrinhos na sala de aula. 3. ed. São Paulo: Contexto, 2006. p.7-30.

VESENTINI, J. W. Apresentação: Geografia e liberdade. Seleção de Textos. São Paulo, 1986.

VIADANA, A. G. A teoria dos refúgios florestais aplicada ao Estado de São Paulo. Rio Claro: A. G. Viadana, 2002.

\title{
Correspondência do autor:
}

\author{
Pedro Dias Mangolini Neves \\ pmangolini@hotmail.com \\ Felipe Gomes Rubira \\ felipe_rubira@hotmail.com
}

ARTIGO RECEBIDO EM: 20/04/2017

REVISADO PELO AUTOR EM: 08/11/2017

ACEITO PARA PUBLICAÇÃO EM: 08/11/2017 